\title{
Prevelance of Scabies among School Going Children in Kashmir
}

\author{
Mubashar Mashqoor Mir ${ }^{1 *}$ and Mohammad Sarwar Mir ${ }^{2}$ \\ ${ }^{1}$ Post Graduate Department of Dermatology, India \\ ${ }^{2}$ Department of Hospital Administration, SKIMS, India \\ *Corresponding author: Mohammad Sarwar Mir, Senior Resident, Department of Hospital Administration, India

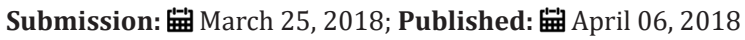

\begin{abstract}
Background: Scabies is a worldwide contagious skin disease. School environment makes students vulnerable to cross-transmission of communicable skin diseases.

Aim: This study aims to estimate the prevalence of scabies amongst school students and to determine the predisposing factors of scabies infestation in public and private schools.

Methods: This was a cross-sectional descriptive study conducted over a period two months. Students were selected from different schools and grades with a total of 3000 .

Results: Scabies prevalence was $4.8 \%$ in the study group. The prevalence was higher in public schools than private schools and in boys more than girls.

Conclusion: Scabies remains a significant public health problem. Regular screenings and periodic health education programs for students and their parents promoting health awareness and attitudes are of prime importance.
\end{abstract}

Keywords: School students; Scabies; Prevalence

\section{Introduction}

Scabies is a contagious skin infestation that spreads by direct and indirect contact, affecting several million people, causing an increase in new cases each year. It is a global disease that can occur in both genders, at all ages, in all ethnic groups, and at all socioeconomic levels [1].

It is a condition that affects families, particularly young children as they are one of the most vulnerable group, followed by older children and young adults [2]. The primary contributing factors to contracting scabies appear to be poor living conditions, coupled with bad hygiene with a complex relationship between these factors [3]. A person's nutritional status has been reported as a significant risk factor in a scabies outbreak, and malnutrition may predispose individuals to crusted scabies [4]. A WHO report, which collated data from 18 prevalence studies conducted between 1971 and 2001, reported scabies prevalence ranging from $0.2 \%$ to $24 \%$ with cyclical epidemics occurring at intervals of 10 to 15 years [5].

Skin disorders are the most frequently diagnosed condition in school pupils, in both developing and industrialized countries. The school environment makes pupils vulnerable to cross-transmission of communicable skin diseases, which can then be passed on to family members [6]. This study aimed to evaluate the prevalence of scabies amongst school going children in Kashmir.

\section{Methods}

It was a descriptive cross-sectional study, conducted in six schools (3 private and 3 public) in Srinagar. The study was conducted during April 2014. The structured questionnaire designed and pretested. It had following points:

i. Socioeconomic data, which included: age, gender, number of family members sharing the same room, level of education and the occupation of both parents.

ii. Clinical diagnosis via general examination, history taking and clinical local examination for signs of scabies.

A student was considered to have scabies, if two of the following requirements were fulfilled: pruritus which intensified at night, presence of the lesions for $>2$ weeks, and at least one more family member with similar lesions. 


\section{Data entry and statistical analysis}

Data was collected, coded and analyzed using SPSS software (Version 20) on Windows 7, and a simple descriptive analysis in the form of means and standard deviations was calculated for numerical data.

\section{Results}

Out of total 3000 students examined, 144 students had scabies yielding a prevelance of $4.8 \%$ (Tables $1-3$ ).

Table 1: School pupil's distribution regarding public and private schools.

\begin{tabular}{|c|c|c|}
\hline Demography & Number & Percentage \\
\hline Private & 1856 & $61.87 \%$ \\
\hline Public & 1144 & $31.13 \%$ \\
\hline Total & 3000 & $100.0 \%$ \\
\hline
\end{tabular}

Table 2: Gender of positive cases (Total positive cases=144).

\begin{tabular}{|c|c|c|}
\hline Gender & Number & Percentage \\
\hline Boys & 84 & $58.33 \%$ \\
\hline Girls & 60 & $41.67 \%$ \\
\hline Total & 144 & $100.0 \%$ \\
\hline
\end{tabular}

Table 3: School distribution of positive cases (Total positive cases=144).

\begin{tabular}{|c|c|c|}
\hline Demography & Number & Percentage \\
\hline Private & 67 & $46.52 \%$ \\
\hline Public & 77 & $53.47 \%$ \\
\hline Total & 144 & $100.0 \%$ \\
\hline
\end{tabular}

\section{Discussion and Conclusion}

Scabies is a globally neglected public health problem in spite of its huge burden from secondary complication, in the most susceptible vulnerable group, children. Scabies is a contagious skin infestation that spreads by direct and indirect contact, affecting several million people, causing an increase in new cases each year. It is a global disease that can occur in both genders, at all ages, in all ethnic groups, and at all socioeconomic levels .It is a condition that affects families, particularly young children as they are one of the most vulnerable group, followed by older children and young adults. The primary contributing factors to contracting scabies appear to be poor living conditions, coupled with bad hygiene with a complex relationship between these factors.

Scabies remains a significant public health problem; it is common in childhood and affects populations from different social levels. Although scabies is a common disease, its diagnosis could be challenging and difficult to establish. We concluded that specific measures need to be undertaken in order to eliminate this disease at various levels comprising of schools, parents and students. This important task can be accomplished through school health program which includes: Regular screening of students by doctors, especially during the seasonal spread of the disease and ensuring the availability of drugs for thorough treatment of all family members to ensure complete cure and recovery from the disease.

Our results revealed that the prevalence of scabies was $4.8 \%$. Comparable findings reported by [7] showed the prevalence in Egyptian primary schools (Kafr el-Sheikh) was $4.4 \%$ and likewise for Sohag [8]. A high prevalence rate of $10.16 \%$ was reported amongst Indian children, which may also be the result of a high density overcrowded population [9].

\section{References}

1. El-Sherbiny NA (2006) Epidemiological Study of Scabies in primary schools, Fayoum governorate Egypt. J Primary Health Care Gen Practice 1(2): $1-5$.

2. Hay RJ, Steer AC, Engelman D, Walton S (2015) Scabies in the developing world - its prevalence, complications and management. Clin Microbiol Infect 18(4): 313-323.

3. Walton SF, Holt DC, Currie BJ, Kemp DJ (2004) Scabies: new future for a neglected disease. Adv Parasitol 57: 309-376.

4. Roberts LJ, Huffam SE, Walton SF, Currie BJ (2005) Crusted scabies: clinical and immunological findings in seventy-eight patients and a review of the literature. J Infect 50(5): 375-381.

5. WHO (2005) World Health Organization Epidemiology and management of common skin diseases in children in developing countries. Geneva, Switzerland.

6. Saurabh S, Sahu SK, Sadishkumar A, et al. (2013) Screening for skin diseases among primary school children in a rural area of Puducherry. Indian J Dermatol Venereol Leprol 79(2): 268.

7. Hegab DH, Kato AM, Kabbash AI, Dabish GM (2015) Scabies among primary school children in Egypt: socio-medical environmental study in Kafr el-Sheikh administrative area. Clin Cosmet Investig Dermatol 8: 105-111.

8. Ezz el-Dawela R, Fatehy AN, Abd elmoneim AA (2012) Prevalence of skin diseases among school children: a survey in the Sohag Governorate. JEWDS 9(1): 47-51.

9. Sardana K, Mahajan S, Sarkar R, et al. (2009) The spectrum of skin disease among Indian children. Pediatr Dermatol 26(1): 6-13.
Creative Commons Attribution 4.0 International License

For possible submissions Click Here

\section{Submit Article}

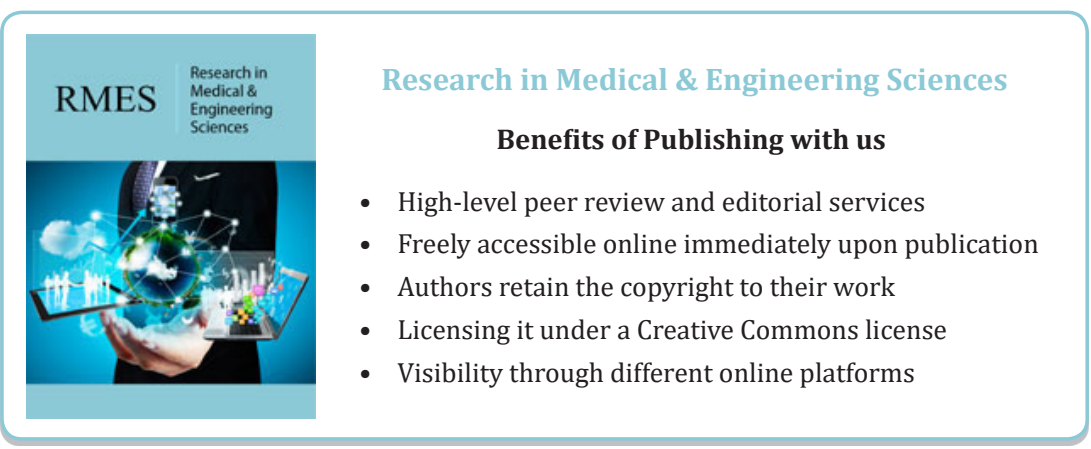

